\title{
Effect of single tablet of fixed-dose amlodipine and atorvastatin on blood pressure/lipid control, oxidative stress, and medication adherence in type 2 diabetic patients
}

Masami Tanaka*, Risa Nishimura, Takeshi Nishimura, Toshihide Kawai, Shu Meguro, Junichiro Irie, Yoshifumi Saisho and Hiroshi Itoh

\begin{abstract}
Background: Oxidized low-density lipoprotein (LDL) plays central roles in the formation and progression of atherosclerotic lesions. Malondialdehyde (MDA)-modified LDL (MDA-LDL) is speculated to be generated as a result of oxidative stress in the human body. Because both amlodipine and atorvastatin have been reported to reduce oxidative stress, it is expected that both drugs would have a favorable influence to reduce oxidative stress.
\end{abstract}

Objective: The objective of this study was to investigate the effects of a single pill of amlodipine $(5 \mathrm{mg})$ /atorvastatin $(10 \mathrm{mg})$ on oxidative stress, blood pressure/lipid control and adherence to medication in patients with type 2 diabetes.

Methods: This combination tablet was administered to 29 patients (16 male), and MDA-LDL, blood pressure, lipid profile, renal/liver function, CPK, hs-CRP, adiponectin, BNP, and HbA1c were measured at baseline, 6, and 12 months, and baPWV and mean IMT were measured at baseline and 12 months. Medication adherence was examined using a questionnaire at 6 months.

Results: MDA-LDL was decreased significantly. LDL-C, TG, and $\mathrm{Cr}$ were significantly decreased at 6 and 12 months compared with baseline. eGFR was increased at 6 months, and urinary albumin/creatinine ratio was decreased at 12 months. BNP was decreased at 6 and 12 months, and adiponectin was increased at 12 months. Both mean IMT and baPWV were significantly decreased. The results of the questionnaire showed that $93 \%$ of patients were satisfied with this medication. No severe adverse event was observed.

Conclusion: This combination tablet controlled both hypertension and dyslipidemia well in type 2 diabetic patients. The deceases in mean IMT and baPWV might suggest the improvement of atherosclerosis by this medication, which could be caused by the reduction of oxidative stress measured by MDA-LDL. In addition, this medication is expected to improve medication adherence.

Keywords: Malondialdehyde-modified low-density lipoprotein, Oxidative stress, Amlodipine, Atorvastatin, Diabetes mellitus, Hypertension, Dyslipidemia, Atherosclerosis, Medication adherence, Combination tablet

*Correspondence: tana176k@sepia.ocn.ne.jp

Department of Internal Medicine, School of Medicine, Keio University,

Tokyo, Japan 


\section{Background}

Oxidized low-density lipoprotein (LDL), which is produced through modification of LDL by oxidation, plays central roles in the formation and progression of atherosclerotic lesions [1]. Malondialdehyde (MDA)-modified LDL (MDA$\mathrm{LDL}$ ), a representative oxidized LDL [2], is speculated to be generated as a result of oxidative stress in the human body. It is suggested that MDA-LDL is involved in many processes of atherosclerosis such as vascular intima injury and foam cell formation [3,4]. Therefore, MDA-LDL has attracted attention as a risk factor for macrovascular disease, such as ischemic heart disease and cerebral infarction.

Investigation of diabetic patients with a history of coronary heart disease has shown that those with increased plasma MDA-LDL concentration have a significantly higher risk of coronary heart disease [5]. Moreover, it has been shown that the risk of restenosis after percutaneous coronary intervention is high if the concentration of MDA-LDL is elevated [6]. It is reported that MDA-LDL concentration in patients with cerebral infarction is significantly higher than that in those without, at any age [7]. In addition, type 2 diabetes mellitus per se is an important risk factor for macrovascular disease irrespective of the history of coronary heart disease or cerebrovascular disease [8]. Therefore, it is suggested that measurement of the serum concentration of MDA-LDL would be useful for the prevention of coronary heart disease and cerebrovascular disease in patients with type 2 diabetes mellitus.

Both amlodipine, which is used to treat hypertension and angina pectoris, and atorvastatin, which is used to treat hypercholesterolemia/familial hypercholesterolemia, have been reported to reduce oxidative stress [9]. Therefore, it is expected that both drugs would have a favorable influence to reduce oxidative stress. Moreover, there is accumulating evidence that these medications can be used for the prevention of coronary heart disease and cerebral infarction [10-13].

In this study, we prospectively investigate the impact of combination therapy with amlodipine and atorvastatin on plasma MDA-LDL level in patients with type 2 diabetes mellitus and concomitant hypertension and hypercholesterolemia. We used a fixed combination tablet containing $5 \mathrm{mg}$ amlodipine and $10 \mathrm{mg}$ atorvastatin. This study hypothesizes that simplification of patients' prescribed medication by using a combination tablet will improve medication adherence. Therefore, in this study, a questionnaire survey about medication adherence was also conducted.

\section{Subjects and methods \\ Subjects}

The subjects were 29 Japanese outpatients with type 2 diabetes (16 men and 13 women) with complications of hypertension and hypercholesterolemia aged 20 years or older. Patients who could not achieve the lipid control goal of the Japan Atherosclerosis Society (JAS) 2012 Guidelines for prevention of atherosclerotic cardiovascular disease (LDL-cholesterol $(\mathrm{LDL}-\mathrm{C})<100 \mathrm{mg} / \mathrm{dl}$ for patients with prior coronary heart disease and LDL-C $<120 \mathrm{mg} / \mathrm{dl}$ for patients without prior coronary heart disease) [14] and/or who could not achieve the blood pressure-lowering goal of the 2009 Japanese Society of Hypertension guidelines for the management of hypertension $(<130 / 80 \mathrm{mmHg})$ [15] in spite of taking a statin and/or calcium channel blocker for at least three months were enrolled.

\section{Methods}

MDA-LDL, blood pressure, LDL-C, high-density lipoprotein cholesterol (HDL-C), triglyceride (TG), serum creatinine $(\mathrm{Cr})$, estimated glomerular filtration ratio (eGFR), urinary albumin-creatinine ratio (ACR), aspartate aminotransferase (AST), alanine aminotransferase (ALT), $\gamma$-glutamyl transferase (GTP), creatine phosphokinase (CPK), high-sensitivity $\mathrm{C}$-reactive protein (hsCRP), adiponectin, brain natriuretic peptide (BNP) and glycosylated hemoglobin A1c (HbA1c) were measured at baseline and 6 and 12 months after the start of administration of this combination tablet and compared. MDA-LDL was measured using an enzyme-linked immunosorbent assay as reported previously $[6,16]$. LDL-C was calculated using the Friedewald formula (LDL-C $=$ total cholesterol (TC)-HDL-C-TG/5). ACR was measured by a turbidimetric immunoassay with a Superior-Microalbumin kit (Daiichi Pharmaceutical Co., Tokyo, Japan) and the Jaffé reaction, using an automated analyzer. hs-CRP was measured by a latex particle-enhanced immunoassay with the nephelometry method (LABOSPECT 008; Hitachi, Tokyo, Japan), using an hs-CRP kit from Mitsubishi Chemical Medicine (Tokyo, Japan). BNP was measured by a fluorescence enzyme immunoassay, using a monoclonal antibody (E-test, Tosoh II BNP; Tosoh, Tokyo, Japan). Adiponectin was measured by a latex particle-enhanced immunoassay as reported previously [17]. HbA1c was determined by HPLC (Toso, Tokyo, Japan) and presented as the equivalent National Glycohemoglobin Standardization Program (NGSP) value.

Brachial-ankle pulse wave velocity (baPWV) and mean intima-media thickness (IMT) were measured at baseline and 12 months after the start of administration and compared. baPWV was measured after 5 min of bed rest using a BP-203RPE III (form PWV/ABI) device (Omron Healthcare, Kyoto, Japan). IMT was measured by ultrasonography B-mode imaging, using a PowerVision ${ }^{\bullet} 6000$ ultrasound machine (Toshiba, Tokyo, Japan).

During the study period, the type and dose of medications that might influence glycemic, blood pressure and/or lipid control were not changed in principle. We verified eligibility of the patients at outpatient medical examinations 
by asking them whether they took this combination tablet as instructed by the doctors in charge.

In order to investigate medication adherence to this combination tablet, we conducted a questionnaire survey. The questionnaire consisted of questions about 1 ) the degree of satisfaction with taking the combination tablet, 2) reason(s) why the patient thinks it is good to take the combination tablet, 3) desire to continue taking the combination tablet in the future, and 4) feelings about the reduction in the number of tablets the patient is taking. They wrote the answers to the multiple choice questions themselves.

In order to investigate the effects of patient characteristics on medical adherence, we performed multivariate analyses. We scored the results of the questionnaire as follows: 'Do you think it is good to take this combination tablet?': very good 3, good 2, not good 1; 'Do you want to continue taking this combination tablet?': yes, very much 4 , I think so 3 , not very much 2 , absolutely not 1 ; 'Do you think that even a decrease in one medication is a good thing?': yes, very much 4 , I think so 3 , not very much 2 , I completely disagree 1 . Then, stepwise regression analyses were performed using the following factors as independent variables: gender $(\operatorname{men}=1$, women $=2)$, age, duration of diabetes, BMI, and baseline HbA1c.

This study was approved by the ethical committee of Keio University School of Medicine. Doctors gave the patients a sufficient explanation of this clinical study. After confirming that the patients understood and agreed to take part, written informed consent was obtained.

\section{Statistical analysis}

Results were expressed as mean \pm standard deviation. Data analyses were performed using the $\mathrm{JMP}^{\circ}$ software package, version 6 (SAS Japan Institute Ltd., Tokyo, Japan) for Windows ${ }^{\oplus}$. Paired $t$-test was used to assess the significance of differences between values obtained before and 6 and 12 months after the start of administration of the combination tablet. Values of $p<0.05$ were considered statistically significant (two-tailed analysis).

\section{Results}

Baseline characteristics of the patients are shown in Table 1. Age, body mass index, duration of diabetes and HbA1c were $58.9 \pm 11.0$ years, $26.2 \pm 5.4 \mathrm{~kg} / \mathrm{m}^{2}, 14.4 \pm 6.2$ years, and $8.3 \pm 1.6 \%$, respectively. Many patients had complications of micro- and macrovascular disease.

As shown in Figure 1, after administration of the combination tablet, MDA-LDL decreased significantly compared with baseline $(69.2 \pm 25.7$ at baseline $\rightarrow 59.3 \pm 18.3$ at 6 months $(\mathrm{p}<0.05) \rightarrow 51.4 \pm 21.4 \mathrm{U} / \mathrm{L}$ at 12 months $(\mathrm{p}<0.01))$. Both systolic and diastolic blood pressure decreased significantly (systolic: $150.2 \pm 12.2$ at baseline $\rightarrow 136.2 \pm 17.4$ at 6 months $(\mathrm{p}<0.01) \rightarrow 131.5 \pm 10.2 \mathrm{mmHg}$ at 12 months $(\mathrm{p}<0.01)$, diastolic: $87.3 \pm 9.2$ at baseline $\rightarrow 82.0 \pm 9.3$ at 6 months $(\mathrm{p}<$ $0.01) \rightarrow 78.0 \pm 6.6 \mathrm{mmHg}$ at 12 months $(\mathrm{p}<0.01)$ ). LDL-C decreased significantly from $110.8 \pm 33.7 \mathrm{mg} / \mathrm{dl}$ at baseline to $82.3 \pm 26.7 \mathrm{mg} / \mathrm{dl}$ at 6 months $(\mathrm{p}<0.01)$, and to $81.3 \pm 25.1 \mathrm{mg} / \mathrm{dl}$ at 12 months $(\mathrm{p}<0.01)$. HDL-C did not change significantly $(48.9 \pm 12.7 \mathrm{mg} / \mathrm{dl}$ at baseline $\rightarrow 49.3 \pm 13.6 \mathrm{mg} / \mathrm{dl}$ at 6 months $\rightarrow 47.7 \pm 13.9 \mathrm{mg} / \mathrm{dl}$ at

Table 1 Patient characteristics at baseline $(n=29)$

\begin{tabular}{|c|c|c|c|}
\hline Gender (n) & Male 16 Female 13 & Hypoglycemic agent (n) & \\
\hline Age (years) & $58.9 \pm 11.0$ & $\mathrm{OHA}$ & 16 \\
\hline BMI $\left(\mathrm{kg} / \mathrm{m}^{2}\right)$ & $26.2 \pm 5.4$ & Insulin & 2 \\
\hline Diabetes duration (years) & $14.4 \pm 6.2$ & OHA+insulin & 10 \\
\hline HbA1c (\%) & $8.3 \pm 1.6$ & Antihypertensive agent (n) & \\
\hline Diabetic complications (n) & & $\mathrm{CCB}$ & 17 \\
\hline Neuropathy & 18 & ARB & 21 \\
\hline Retinopathy & 9 & ACE inhibitor & 4 \\
\hline Nephropathy & 13 & Diuretic & 3 \\
\hline Macrovascular disease (n) & & B blocker & 2 \\
\hline Cerebral infarction & 4 & Antihyperlipidemic agent (n) & \\
\hline \multirow[t]{5}{*}{ Angina/myocardial infarction } & 4 & Statin & 17 \\
\hline & & Ezetimibe & 1 \\
\hline & & Antiplatelet agent (n) & \\
\hline & & Aspirin & 5 \\
\hline & & Clopidogrel & 1 \\
\hline
\end{tabular}

The results are shown as mean \pm standard deviation, or number of patients. 


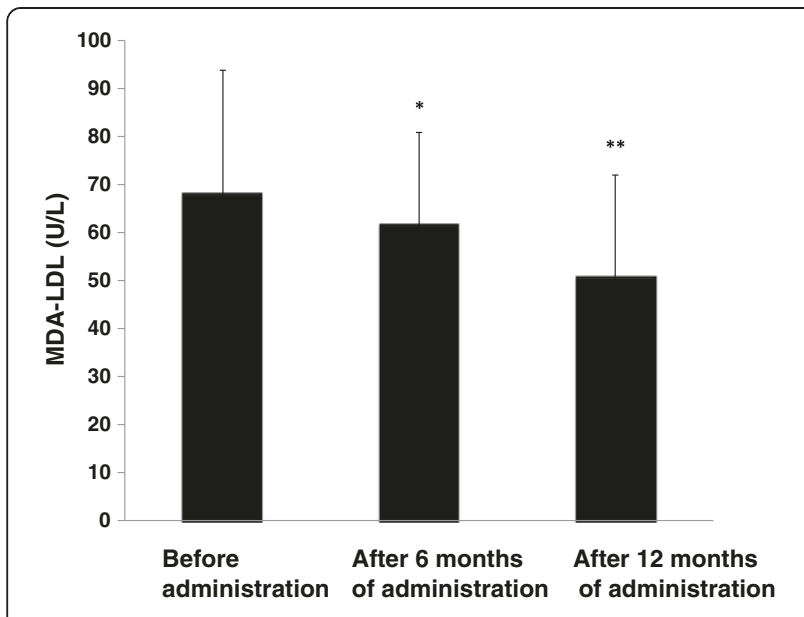

Figure 1 Change in plasma MDA-LDL concentration. The results are shown as mean \pm standard deviation. Comparison with the value before administration of the combination tablet. ${ }^{*} p<0.05,{ }^{* *} p<0.01$ (paired $t$-test)

12 months). On the other hand, TG decreased significantly $(193.9 \pm 127.9 \mathrm{mg} / \mathrm{dl}$ at baseline $\rightarrow 144.7 \pm 71.0 \mathrm{mg} / \mathrm{dl}$ at 6 months $(\mathrm{p}<0.05) \rightarrow 151.2 \pm 91.6 \mathrm{mg} / \mathrm{dl}$ at 12 months $(\mathrm{p}<0.01))$.

Compared with baseline, serum $\mathrm{Cr}$ was decreased significantly at both 6 and 12 months $(0.77 \pm 0.19 \mathrm{mg} / \mathrm{dl}$ at baseline $\rightarrow 0.73 \pm 0.17 \mathrm{mg} / \mathrm{dl}$ at 6 months $(\mathrm{p}<0.01) \rightarrow 0.74 \pm$ $0.19 \mathrm{mg} / \mathrm{dl}$ at 12 months $(\mathrm{p}<0.05))$, and eGFR was increased significantly at 6 months $(77.0 \pm 30.4$ at baseline $\rightarrow 80.2 \pm 27.4$ at 6 months $(\mathrm{p}<0.01) \rightarrow 78.6 \pm 25.0 \mathrm{ml} /$ $\mathrm{min} / 1.73 \mathrm{~m}^{2}$ at 12 months). ACR was decreased significantly at 12 months $(67.6 \pm 118.4$ at baseline $\rightarrow 42.9 \pm 70.5$ at 6 months $\rightarrow 39.5 \pm 67.2 \mathrm{mg} / \mathrm{gCr}$ at 12 months $(\mathrm{p}<0.05))$.

As shown in Table 2, AST, ALT, yGTP, CPK, hs-CRP, and $\mathrm{HbA} 1 \mathrm{c}$ did not change significantly during the observation period.

As shown in Figure 2, BNP was significantly decreased at both 6 and 12 months $(19.5 \pm 14.0$ at baseline $\rightarrow 15.4 \pm 12.5$ at 6 months $(\mathrm{p}<0.01) \rightarrow 15.3 \pm 11.2 \mathrm{pg} / \mathrm{ml}$ at 12 months $(\mathrm{p}<$ $0.01)$ ), and adiponectin was increased at 12 months $(7.64 \pm$ 4.49 at baseline $\rightarrow 7.82 \pm 4.73$ at 6 months $\rightarrow 8.15 \pm 5.25 \mu \mathrm{g} / \mathrm{ml}$ at 12 months $(\mathrm{p}<0.05))$.
As shown in Figure 3, compared with baseline, both baPWV and mean IMT improved significantly (baPWV: $1768.0 \pm 477.4$ at baseline $\rightarrow 1689.9 \pm 389.5 \mathrm{~cm} / \mathrm{sec}$ at 12 months $(\mathrm{p}<0.05)$, mean IMT: $0.91 \pm 0.21$ at baseline $\rightarrow 0.82 \pm 0.24 \mathrm{~mm}$ at 12 months $(\mathrm{p}<0.01))$.

The results of the questionnaire survey are shown in Table 3. Answers were obtained from 27 patients. Of the patients, 93\% (25/27) were satisfied with this combination tablet (3a). The most common reason for satisfaction was that "LDL-C was decreased sufficiently". The second most common reason was that "blood pressure was decreased sufficiently" (3b).

Almost all $(26 / 27)$ patients answered that they wanted to continue taking this medication (3c), and 89\% (24/27) answered that even a decrease of one tablet is a good thing (3d).

Stepwise regression analyses demonstrated that none of the factors investigated was identified as an independent determinant of the scores of three questions (1): gender $\beta=$ $0.15, \mathrm{p}=0.54$; age $\beta=-0.20, \mathrm{p}=0.58$, duration of diabetes $\beta=0.04, p=0.90$, BMI $\beta=-0.25, p=0.30$, baseline HbA1c $\beta=0.22, p=0.45,3)$ : gender $\beta=0.12, p=0.60$, age $\beta=0.47$, $\mathrm{p}=0.14$, duration of diabetes $\beta=-0.32, \mathrm{p}=0.30$, BMI $\beta=$ $0.068, \mathrm{p}=0.78$, baseline HbA1c $\beta=0.45, \mathrm{p}=0.13$; 4): gender $\beta=0.24, p=0.33$, age $\beta=-0.61, p=0.086$, duration of diabetes $\beta=0.35, p=0.31$, BMI $\beta=-0.042, p=0.87$, baseline HbA1c $\beta=-0.29, \mathrm{p}=0.35$ ).

No severe adverse event occurred, and all 29 patients could continue taking this combination tablet.

\section{Discussion}

After the administration of a fixed combination tablet containing $5 \mathrm{mg}$ amlodipine and $10 \mathrm{mg}$ atorvastatin, blood pressure, LDL-C, TG, and MDA-LDL were significantly improved in type 2 diabetic patients with hypertension and dyslipidemia. In addition, baPWV and mean IMT, which are markers of atherosclerosis, also improved.

The achieved LDL-C, systolic and diastolic blood pressure were $81.3 \pm 25.1 \mathrm{mg} / \mathrm{dl}, 131.5 \pm 10.2 \mathrm{mmHg}$, and $78.0 \pm 6.6 \mathrm{mmHg}$, respectively. LDL-C $(<120 \mathrm{mg} / \mathrm{dl})$ and diastolic blood pressure $(<80 \mathrm{mmHg})$ reached the target in the Japanese guidelines, and systolic blood pressure

Table 2 Changes in clinical parameters

\begin{tabular}{|c|c|c|c|}
\hline & Before administration & After 6 months of administration & After 12 months of administration \\
\hline AST (IU/L) & $27.8 \pm 13.5$ & $26.5 \pm 12.7$ & $24.8 \pm 11.1$ \\
\hline ALT (IU/L) & $31.8 \pm 23.6$ & $30.8 \pm 18.2$ & $26.5 \pm 14.0$ \\
\hline ү-GTP (IU/L) & $44.7 \pm 42.0$ & $48.0 \pm 49.6$ & $45.7 \pm 51.8$ \\
\hline CPK (IU/L) & $109.6 \pm 57.3$ & $109.8 \pm 53.0$ & $109.2 \pm 69.3$ \\
\hline hs-CRP (mg/dL) & $0.13 \pm 0.18$ & $0.11 \pm 0.15$ & $0.10 \pm 0.13$ \\
\hline HbA1c (\%) & $8.3 \pm 1.6$ & $8.5 \pm 1.5$ & $8.3 \pm 1.6$ \\
\hline
\end{tabular}

The results are shown as mean \pm standard deviation.

No parameter showed a significant change during the course of this study. 

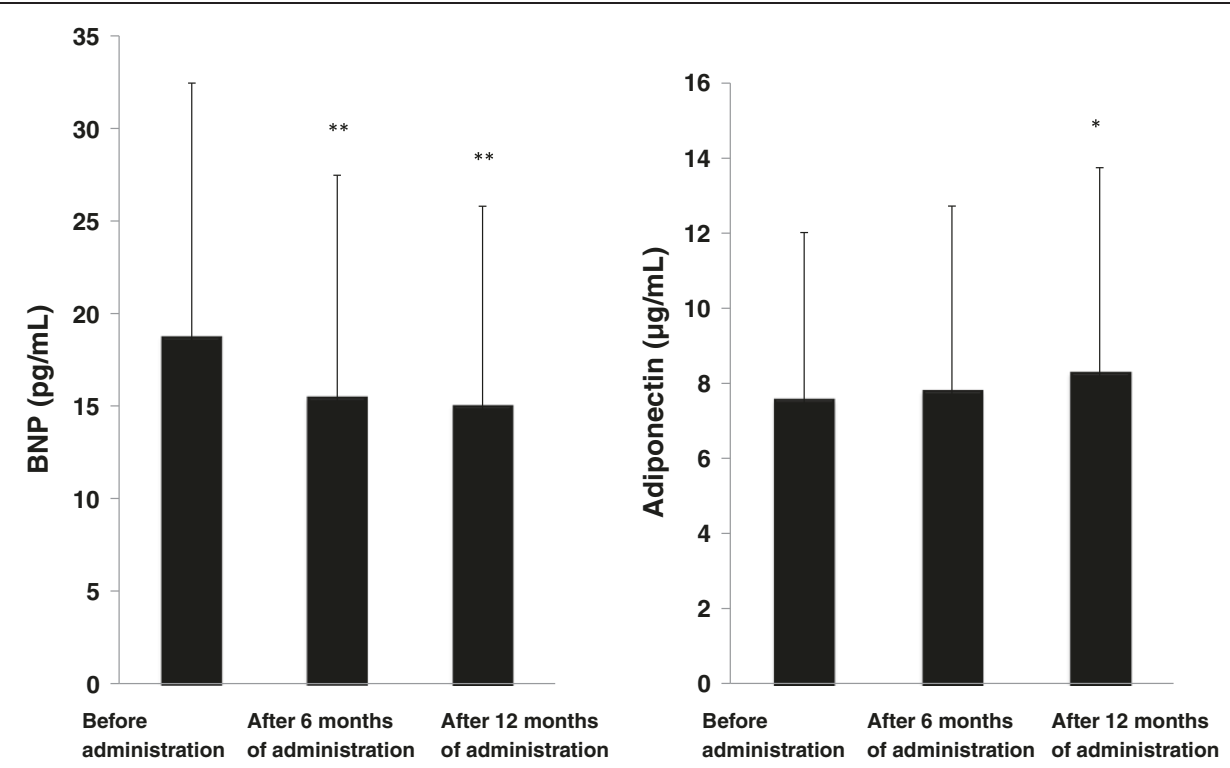

Figure $\mathbf{2}$ Changes in plasma concentration of BNP and adiponectin. The results are shown as mean \pm standard deviation. Comparison with the value before administration of the combination tablet. ${ }^{*} p<0.05,{ }^{* *} p<0.01$ (paired $t$-test).

almost reached the goal $(<130 \mathrm{mmHg})$. Therefore, it was shown that this combination tablet could control both hypertension and hypercholesterolemia, which are the two major risk factors for atherosclerosis. Taken together with the report that thickening of IMT is an independent, significant predictor of cerebral infarction and coronary artery disease $[18,19]$, this medication is considered to be very useful for the prevention of macrovascular complications in type 2 diabetic patients.

In the Anglo-Scandinavian Cardiac Outcomes Trial-Lipid Lowering Arm (ASCOT-LLA), it was shown that treating hypercholesterolemia could prevent coronary heart disease in hypertensive patients taking antihypertensive medication "at high risk", even though their total cholesterol was $250 \mathrm{mg} / \mathrm{dl}$ or less [13]. Patients "at high risk" means that they have several characteristics including old age (55 years or more), male, smoking habit, type 2 diabetes, microalbuminuria, and left ventricular hypertrophy. Therefore, the results of ASCOT-LLA can be applied to many patients we encounter in daily clinical settings. This indicates the usefulness of treating not only hypertension but also dyslipidemia at the same time in hypertensive patients.

Another analysis of ASCOT-LLA showed that the incidence of cardiovascular events was significantly decreased

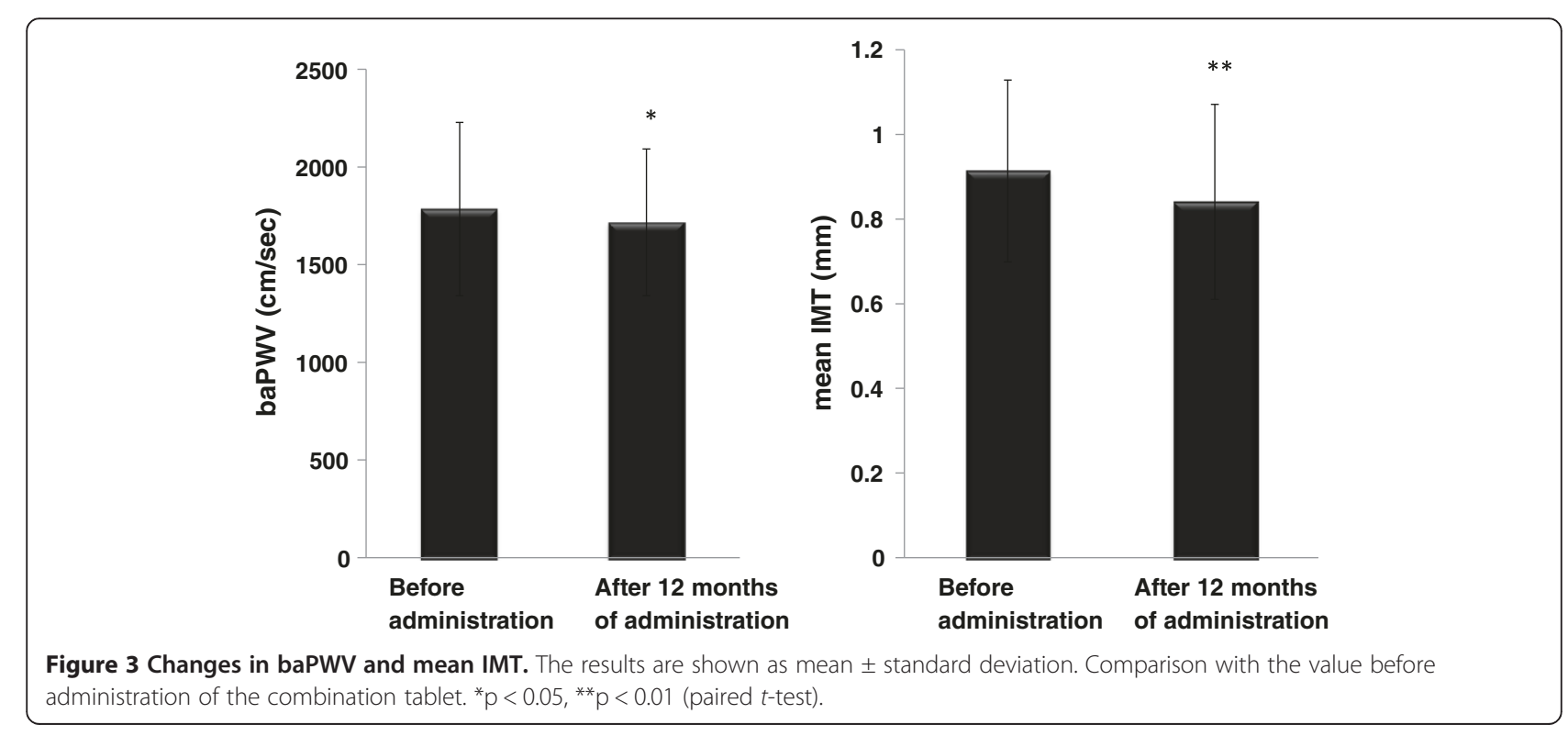


Table 3 Results of questionnaire survey on medication adherence

\begin{tabular}{lc}
\hline a. Do you think it is good to take this combination tablet? & \\
\hline Very good & 8 \\
Good & 17 \\
Not good & 0 \\
No answer & 2 \\
\hline
\end{tabular}

b. Reason(s) why you think that it was good to take this combination tablet

LDL-C was decreased sufficiently $\quad 12$

Blood pressure was decreased sufficiently 10

Tablet is small and easy to swallow

I do not have to discriminate morning and evening doses

Number of times taking medication is reduced

Number and dose of medications taken in one day is reduced 6

Number and dose of medications taken at one time is reduced 8

c. Do you want to continue taking this combination tablet?

\begin{tabular}{ll}
\hline Yes, very much & 12
\end{tabular}

I think so

14

Not very much

Absolutely not

No answer

0

d. Do you think that even a decrease in one medication is a good thing?

Yes, very much

19

I think so

Not very much

I completely disagree

I have no idea

$\mathrm{N}$ : number of answers.

3b: Multiple answers were allowed.

in patients treated with amlodipine and atorvastatin compared with patients treated with atenolol and atorvastatin, even though there was no significant difference in blood pressure, TC, or LDL-C between the two patient groups [20]. Consequently, from the perspective of cardiovascular event prevention, it was suggested that the combination of amlodipine and atorvastatin might have high efficacy and that this fixed-dose combination tablet is very important because patients can take both amlodipine and atorvastatin by taking only one tablet.

Because MDA-LDL is thought to be involved in many steps of atherosclerosis, it is a promising candidate as a risk factor for atherosclerosis other than established risk factors such as hypertension, diabetes, and LDL-C. It has been shown that the plasma concentration of MDALDL is increased in patients with unstable carotid artery plaques [21]. In the present study, this combination tablet decreased MDA-LDL, which suggests the possibility that this medication might directly intervene in many processes of atherosclerosis. Taking these findings together with the result that this combination tablet improved baPWV and mean IMT, this medication is thought to be highly promising as an anti-atherosclerosis drug.

MDA-LDL has been reported to exert direct cytotoxicity on endothelial cells, to promote synthesis and secretion of adhesion molecules, to increase platelet aggregation and monocyte adhesion, and to enhance foam cell formation in atherosclerotic lesions, all of which lead to remodeling of vessel walls $[3,4]$. The level of circulating MDA-LDL is reported to be elevated in patients with diabetes [22]. The mechanisms underlying the increase in MDA-LDL in diabetic patients are not clear, although enhancement of lipid peroxidation might be involved [23]. The main causes of death of diabetic patients are macrovascular diseases caused by severe atherosclerosis. Considering this, the observation that this combination tablet decreased MDALDL significantly might have clinical significance from the perspective of macrovascular disease prevention. Measurement of MDA-LDL, especially in diabetic patients, is expected to have a clinical impact.

During the observation period, $\mathrm{Cr}$ and ACR decreased, eGFR increased, and BNP decreased significantly. All of these results may reflect the reno- and cardio- protective effects of this combination tablet. Although statins have been reported to possess a reno-protective effect, it was shown that the reno-protective effect of atorvastatin is stronger than that of other statins [24]. Atorvastatin has been shown to improve eGFR and $\mathrm{Cr}$ clearance in several sub-analyses from large scale clinical trials such as the Collaborative Atorvastatin Diabetes Study (CARDS) [25], the Treating to New Targets (TNT) [26], and the Greek atorvastatin and coronary heart disease evaluation (GREACE) [27].

As one of the mechanisms underlying the renoprotective effect of atorvastatin, the possibility that atorvastatin might suppress podocyte injury was reported recently [28]. In a sub-analysis of TNT, administration of atorvastatin significantly reduced hospitalization due to heart failure [29]. Therefore, as a mechanism of BNP lowering in this study, there is a possibility that the pleiotropic effect of atorvastatin was added to the blood pressure-lowering effect of amlodipine.

In the present study, it was shown that the concentration of adiponectin was increased after 12 months of administration of this combination tablet. It is reported that when both atorvastatin and amlodipine were administered in patients with coronary heart disease, hypertension and dyslipidemia, the plasma concentration of adiponectin increased [30]. In this study, it is also reported that the increase in adiponectin concentration and improvement ratio of vascular intima function evaluated by flowmediated vasodilation (FMD) method were correlated [30]. Although the underlying mechanism of the improvement of baPWV and mean IMT in this study is not clear, 
increase in adiponectin might be involved, through an antiatherosclerotic action, in addition to blood pressure lowering by amlodipine and LDL-C lowering by atorvastatin.

An improvement in medication adherence leads to an increase in the direct benefit of the medication. It has been reported that as the number of drugs taken in one day increases, medication adherence deteriorates, and that as the number of drugs and times of medication decrease, medication adherence improves [31]. Moreover, it is reported that medication adherence is improved by using a combination tablet [32].

The questionnaire survey about medication adherence in the present study showed high satisfaction with the combination tablet. As a reason for this, many patients stated a sufficient decrease in LDL-C and blood pressure. It is important that patients evaluated both the decrease in number of tablets and the drug efficacy, that is, improvement in blood pressure and dyslipidemia highly. Because $89 \%(24 / 27)$ of patients answered that even a decrease in one tablet is a good thing, the medication adherence to this combination tablet might be very good. Stepwise regression analyses showed that none of gender, age, duration of diabetes, BMI, and baseline HbA1c influenced the results of the questionnaire survey. This might suggest the possibility that this medication improves medication adherence in many patients with a wide variety of backgrounds. However, this should be confirmed by larger scale studies containing a control group. It is reported that if medication adherence is high for 1-2 years after initiation, medication adherence will continue to be high thereafter [33]. Therefore, it is expected that the participants in this clinical trial will continue to take this combination tablet in the future.

This study included many patients with a long duration of diabetes mellitus or poor glycemic control. Many patients had complications of obesity, diabetic microangiopathy, and macroangiopathy. Many patients took an antihypertensive, antidiabetic, or antiplatelet drug. Notwithstanding, no severe adverse event occurred, and all 29 patients could continue taking this combination tablet. Liver function, $\mathrm{CPK}$, and $\mathrm{HbA1c}$ did not deteriorate during the course of the study. Therefore, the safety of this medication appears to be confirmed in high risk patients.

There are some limitations of this study. Firstly, the number of patients included was small. Secondly, this was a single arm study and did not have a control. Finally, the results of our study may not be applicable to the general population or to patients with type 2 diabetes in a primary care setting, because patients who attend university hospitals are selected patients.

\section{Conclusion}

It was shown that a single-pill of amlodipine $(5 \mathrm{mg}) /$ atorvastatin $(10 \mathrm{mg})$ could control both blood pressure and lipid profile well in type 2 diabetic patients with complications of hypertension and dyslipidemia. The deceases in mean IMT and baPWV might suggest the improvement of atherosclerosis by this medication, which could be explained at least in part by the reduction of oxidative stress measured by MDA-LDL. This medication is expected to prevent cardiovascular events through a decrease of oxidative stress and improvement of medication adherence.

\section{Competing interests}

The authors declare that they have no competing interests.

\section{Authors' contribution}

MT, RN and TN disigned and performed this clinical study. TK wrote the paper. SM performed the statistical analyses. II and YS recruited the patients. $\mathrm{HI}$ surpervised the project. All authors read and approved the final manuscript.

Received: 20 November 2013 Accepted: 12 May 2014

Published: 18 May 2014

\section{References}

1. Witztum $J$, Steinberg D: Role of oxidized low density lipoprotein in atherogenesis. J Clin Invest 1991, 88:1785-1792.

2. Kotani K, Maekawa M, Kanno T, Kondo A, Toda N: Manabe: Distribution of immunoreactive malondialdehyde-modified low-density lipoprotein in human serum. Biochim Biophys Acta 1994, 17:121-125.

3. Berliner JA, Heinecke JW: The role of oxidized lipoproteins in atherosclerosis. Free Radic Biol Med 1996, 20:707-727.

4. Steinberg D: Low density lipoprotein oxidation and its pathobiological significance. J Biol Chem 1997, 272:20963-20966.

5. Tanaga K, Bujo H, Inoue M, Mikami K, Kotani K, Takahashi K, Kanno T, Saito $Y$ : Increased circulating malondialdehyde-modified LDL levels in patients with coronary artery diseases and their association with peak sizes of LDL particles. Arterioscler Thromb Vasc Biol 2002, 22:662-666.

6. Shigematsu S, Takahashi N, Hara M, Yoshimatsu H, Saikawa T: Increased incidence of coronary in-stent restenosis in type 2 diabetic patients is related to elevated serum malondialdehyde-modified low-density lipoprotein. Circ J 2007, 71:1697-1702.

7. Uno M, Kitazato KT, Nishi K, Itabe H, Nagahiro S: Raised plasma oxidized LDL in acute cerebral infarction. J Neurol Neurosurg Psychiatry 2003, 74:312-316.

8. Haffner SM, Lehto S, Rönnemaa T, Pyörälä K, Laakso M: Mortality from coronary heart disease in subjects with type 2 diabetes and in nondiabetic subjects with and without prior myocardial infarction. N Engl J Med 1998, 339:229-234.

9. Mason RP, Walter MF, Day CA, Jacob RF: Intermolecular differences of 3-hydroxy-3-methylglutaryl coenzyme $A$ reductase inhibitors contribute to distinct pharmacologic and pleiotropic actions. Am J Cardiol 2005, 96(Suppl):11F-23F.

10. Colhoun HM, Betteridge DJ, Durrington PN, Hitman GA, Neil HA, Livingstone SJ, Thomason MJ, Mackness MI, Charlton-Menys V, Fuller JH: CARDS investigators: Primary prevention of cardiovascular disease with atorvastatin in type 2 diabetes in the Collaborative Atorvastatin Diabetes Study (CARDS): multicenter randomized placebo-controlled trial. Lancet 2004, 364:685-696.

11. Amarenco P, Bogousslavsky J, Callahan A 3rd, Goldstein LB, Hennerici M, Rudolph AE, Sillesen H, Simunovic L, Szarek M, Welch KM, Zivin JA: Stroke Prevention by Aggressive Reduction in Cholesterol Levels (SPARCL) Investigators: High-dose atorvastatin after stroke or transient ischemic attack. N Engl J Med 2006, 355:549-559.

12. Dahlöf B, Sever PS, Poulter NR, Wedel H, Beevers DG, Caulfield M, Collins R, Kjeldsen SE, Kristinsson A, Mclnnes GT, Mehlsen J, Nieminen M, O'Brien E, Ostergren J: ASCOT Investigators: Prevention of cardiovascular events with an antihypertensive regimen of amlodipine adding perindopril as required versus atenolol adding bendroflumethiazide as required, in the Anglo-Scandinavian Cardiac Outcomes Trial-Blood Pressure Lowering Arm (ASCOT-BPLA): a multicentre randomised controlled trial. Lancet 2005, 366:895-906. 
13. Sever PS, Dahlöf B, Poulter NR, Wedel H, Beevers G, Caulfield M, Collins R, Kjeldsen SE, Kristinsson A, McInnes GT, Mehlsen J, Nieminen M, O'Brien E, Ostergren J: ASCOT investigators: Prevention of coronary and stroke events with atorvastatin in hypertensive patients who have average or lower-than-average cholesterol concentrations, in the AngloScandinavian Cardiac Outcomes Trial-Lipid Lowering Arm (ASCOT-LLA): a multicentre randomised controlled trial. Lancet 2003, 361:1149-1158.

14. Teramoto T, Sasaki J, Ishibashi S, Birou S, Daida H, Dohi S, Egusa G, Hiro T, Hirobe K, lida M, Kihara S, Kinoshita M, Maruyama C, Ohta T, Okamura T, Yamashita S, Yokode M, Yokote K: Executive summary of the Japan Atherosclerosis Society (JAS) guidelines for the diagnosis and prevention of atherosclerotic cardiovascular diseases in Japan -2012 version. J Atheroscler Thromb 2013, 20:517-523.

15. Ogihara T, Kikuchi K, Matsuoka H, Fujita T, Higaki J, Horiuchi M, Imai Y, Imaizumi T, Ito S, Iwao H, Kario K, Kawano Y, Kim-Mitsuyama S, Kimura G, Matsubara H, Matsuura H, Naruse M, Saito I, Shimada K, Shimamoto K, Suzuki H, Takishita S, Tanahashi N, Tsuchihashi T, Uchiyama M, Ueda S, Ueshima H, Umemura S, Ishimitsu T, Rakugi H: Japanese Society of Hypertension Committee: The Japanese Society of Hypertension Guidelines for the Management of Hypertension (JSH 2009). Hypertens Res 2009, 32:3-107.

16. Kondo A, Muranaka Y, Ohta I, Notsu K, Manabe M, Kotani K, Saito K, Maekawa M, Kanno T: Relationship between triglyceride concentrations and LDL size evaluated by malondialdehyde-modified LDL. Clin Chem 2001, 47:893-900.

17. Nishimura A, Sawai T: Determination of adiponectin in serum using a latex particle-enhanced turbidimetric immunoassay with an automated analyzer. Clin Chim Acta 2006, 371:163-168

18. Irie $Y$, Katakami N, Kaneto H, Kasami R, Sumitsuji S, Yamasaki K, Tachibana K, Kuroda T, Sakamoto K, Umayahara Y, Ueda Y, Kosugi K, Shimomura I: Maximum carotid intima-media thickness improves the prediction ability of coronary artery stenosis in type 2 diabetic patients without history of coronary artery disease. Atherosclerosis 2012, 221:438-444.

19. Hirano M, Nakamura T, Kitta Y, Takishima I, Deyama J, Kobayashi T, Fujioka D, Saito Y, Watanabe K, Watanabe Y, Kawabata K, Obata JE, Kugiyama K: Shortterm progression of maximum intima-media thickness of carotid plaque is associated with future coronary events in patients with coronary artery disease. Atherosclerosis 2011, 215:507-512.

20. Sever PS, Dahlöf B, Poulter N, Wedel H, Beevers G, Caulfield M, Collins R, Kjeldsen S, Kristinsson A, Mclnnes G, Mehlsen J, Nieminem M, O'brien E, Ostergren J: ASCOT Steering Committee members: Potential synergy between lipid-lowering and blood-pressure-lowering in the AngloScandinavian Cardiac Outcomes Trial. Eur Heart J 2006, 27:2982-2988.

21. Tajika K, Okamatsu K, Takano M, Inami S, Yamamoto M, Murakami D, Kobayashi N, Ohba T, Hata N, Seino Y, Mizuno K: Malondialdehydemodified low-density lipoprotein is a useful marker to identify patients with vulnerable plaque. Circ J 2012, 76:2211-2217.

22. Kondo A, Manabe M, Saito K, Maekawa M, Kanno T: Insulin treatment prevents LDL from accelerated oxidization in patients with diabetes. J Atheroscler Thromb 2002, 9:280-287.

23. Abdel-Wahab MH, Abd- Allah AR: Possible protective effect of melatonin and/or desferrioxamine against streptozotocin-induced hyperglycaemia in mice. Pharmacol Res 2000, 41:533-537.

24. Sandhu S, Wiebe N, Fried LF, Tonelli M: Statins for improving renal outcomes: a meta-analysis. J Am Soc Nephrol 2006, 17:2006-2016.

25. Colhoun HM, Betteridge DJ, Durrington PN, Hitman GA, Neil HA, Livingstone SJ, Charlton-Menys V, Demicco DA, Fuller JH: CARDS Investigators: Effects of atorvastatin on kidney outcomes and cardiovascular disease in patients with diabetes: an analysis from the Collaborative Atorvastatin Diabetes Study (CARDS). Am J Kidney Dis 2009, 54:810-819.

26. Shepherd J, Kastelein JJ, Bittner V, Deedwania P, Breazna A, Dobson S, Wilson DJ, Zuckerman A, Wenger NK: Treating to New Target investigators: Effect of intensive lipid lowering with atorvastatin on renal function in patients with coronary heart disease: the Treating to New Targets (TNT) study. Clin J Am Soc Nephrol 2007, 2:1131-1139.

27. Athyros VG, Mikhailidis DP, Papageorgiou AA, Symeonidis AN, Pehlivanidis A, Bouloukos VI, Elisaf M: The effect of statins versus untreated dyslipidaemia on renal function in patients with coronary heart disease. A subgroup analysis of the Greek atorvastatin and coronary heart disease evaluation (GREACE) study. J Clin Pathol 2004, 57:728-734.

28. Takemoto M, Ishikawa T, Onishi S, Okabe E, Ishibashi R, He P, Kobayashi K, Fujimoto $M$, Kawamura $H$, Yokote $K$ : Atorvastatin ameliorates podocyte injury in patients with type 2 diabetes complicates with dyslipidemia. Diabetes Res Clin Pract 2013, 100:e26-29.

29. Khush KK, Waters DD, Bittner V, Deedwania PC, Kastelein JJ, Lewis SJ, Wenger NK: Effect of high-dose atorvastatin on hospitalizations for heart failure: subgroup analysis of the Treating to New Targets (TNT) study. Circulation 2007, 115:576-583.

30. Li M, Xu A, Lam KS, Cheung BM, Tse HF: Impact of combination therapy with amlodipine and atorvastatin on plasma adiponectin levels in hypertensive patients with coronary artery disease: combination therapy and adiponectin. Postgrad Med 2011, 123:66-71.

31. Schroeder K, Fahey T, Ebrahim S: How can we improve adherence to blood pressure-lowering medication in ambulatory care? Systematic review of randomized controlled traials. Arch Intern Med 2004, 164:722-732.

32. Bangalore S, Kamalakkannan G, Parker S, Messerli FH: Fixed-dose combinations improve medication compliance: a meta-analysis. Am J Med 2007, 120:713-719.

33. Bell KJ, Kirby A, Hayen A, Irwig L, Glasziou P: Monitoring adherence to drug treatment by using change in cholesterol concentration: secondary analysis of trial data. BMJ 2011, 342:d12.

doi:10.1186/1758-5996-6-56

Cite this article as: Tanaka et al:: Effect of single tablet of fixed-dose amlodipine and atorvastatin on blood pressure/lipid control, oxidative stress, and medication adherence in type 2 diabetic patients. Diabetology \& Metabolic Syndrome 2014 6:56

\section{Submit your next manuscript to BioMed Central and take full advantage of:}

- Convenient online submission

- Thorough peer review

- No space constraints or color figure charges

- Immediate publication on acceptance

- Inclusion in PubMed, CAS, Scopus and Google Scholar

- Research which is freely available for redistribution 